NBER WORKING PAPER SERIES

THE "STERN REVIEW" ON THE ECONOMICS OF CLIMATE CHANGE

William D. Nordhaus

Working Paper 12741

http://www.nber.org/papers/w12741

NATIONAL BUREAU OF ECONOMIC RESEARCH

1050 Massachusetts Avenue

Cambridge, MA 02138

December 2006

The author is grateful for helpful comments by Scott Barrett, William Brainard, Partha Dasgupta, Robert Stavins, Nicholas Stern, and John Weyant. The views expressed herein are those of the author(s) and do not necessarily reflect the views of the National Bureau of Economic Research.

(C) 2006 by William D. Nordhaus. All rights reserved. Short sections of text, not to exceed two paragraphs, may be quoted without explicit permission provided that full credit, including $\odot$ notice, is given to the source. 
The "Stern Review" on the Economics of Climate Change

William D. Nordhaus

NBER Working Paper No. 12741

December 2006

JEL No. Q4,Q5

\begin{abstract}
$\underline{\text { ABSTRACT }}$
How much and how fast should the globe reduce greenhouse-gas emissions? How should nations balance the costs of the reductions against the damages and dangers of climate change? This question has been addressed by the recent "Stern Review on the Economics of Climate Change," which answers these questions clearly and unambiguously. We need urgent, sharp, and immediate reductions in greenhouse-gas emissions. An analysis of the "Stern Review" finds that these recommendations depend decisively on the assumption of a near-zero social discount rate. The Review's unambiguous conclusions about the need for extreme immediate action will not survive the substitution of discounting assumptions that are consistent with today's market place.
\end{abstract}

William D. Nordhaus

Yale University, Department of Economics

28 Hillhouse Avenue

Box 208264

New Haven, CT 06520-8264

and NBER

william.nordhaus@yale.edu 
The Stern Review on the Economics of Climate Change ${ }^{1}$

William Nordhaus

November 17, 2006

Opposite ends of the globe

It appears that no two global warming policies on earth are farther apart than the White House and 10 Downing Street. In 2001, President G.W. Bush announced his opposition to binding constraints on greenhouse gas (GHG) emissions. In his letter of opposition, he stated, "I oppose the Kyoto Protocol because it exempts 80 percent of the world, including major population centers such as China and India, from compliance, and would cause serious harm to the U.S. economy." This policy, much like the war in Iraq, was undertaken with no discernible economic analysis. ${ }^{2}$

In stark contrast, the British government in November 2006 presented a comprehensive new study, the Stern Review on the Economics of Climate Change

\footnotetext{
1 The author is grateful for helpful comments by Scott Barrett, William Brainard, Partha Dasgupta, Robert Stavins, Nicholas Stern, and John Weyant.

2 Text of a Letter from the President to Senators Hagel, Helms, Craig, and Roberts, March 13, 2001, http:// www.whitehouse.gov/news/releases/2001/03/20010314.html (downloaded November 13, 2006). There is no record of a fact sheet or other economic analysis accompanying the letter. The Bush Administration's economic analysis was contained in the 2002 Economic Report of the President and the Council of Economic Advisers, published almost a year after President Bush's letter to the Senators. The Economic Report's analysis suggests that the Kyoto Protocol is costly, but its analysis does not show that binding action is economically unwarranted.
} 
(hereafter the Review). ${ }^{3}$ Prime Minister Tony Blair painted a dark picture for the globe at its unveiling, "It is not in doubt that if the science is right, the consequences for our planet are literally disastrous.... [W]ithout radical international measures to reduce carbon emissions within the next 10 to 15 years, there is compelling evidence to suggest we might lose the chance to control temperature rises." 4

The summary in the Review was equally stark: "[T]he Review estimates that if we don't act, the overall costs and risks of climate change will be equivalent to losing at least $5 \%$ of global GDP each year, now and forever. If a wider range of risks and impacts is taken into account, the estimates of damage could rise to $20 \%$ of GDP or more.... Our actions now and over the coming decades could create risks ... on a scale similar to those associated with the great wars and the economic depression of the first half of the 20th century." 5

These results are dramatically different from earlier economic models that use the same basic data and analytical structure. One of the major findings in the economics of climate change has been that efficient or "optimal" economic policies to slow climate change involve modest rates of emissions reductions in the near term, followed by sharp reductions in the

\footnotetext{
${ }^{3}$ All citations in this note were from the online version at http://www.hmtreasury.gov.uk/independent_reviews/stern_review_economics_climate_change/ sternreview_index.cfm (downloaded various dates, November 2006).

${ }^{4}$ PM's comments at launch of Stern Review, http:// www.number10.gov.uk/output/Page10300.asp (downloaded November 13, 2006).

${ }^{5}$ Review, Summary of Conclusions.
} 
medium and long term. We might call this the climate-policy ramp, in which policies to slow global warming increasingly tighten or ramp up over time. ${ }^{6}$

While seemingly counterintuitive, the findings about the climate-policy ramp have survived the tests of multiple alternative modeling strategies, different climate goals, alternative specifications of the scientific modules, and more than a decade of revisions in integrated assessment models. The logic of the climate-policy ramp is straightforward. In a world where capital is productive, the highest-return investments are primarily in tangible, technological, and human capital, including research and development in low-carbon-emissions technologies. As societies become richer in the coming decades, it becomes efficient to shift investments toward policies that intensify the pace of emissions reductions and otherwise slow GHG emissions. The exact mix and timing of emissions reductions depends upon details of costs, damages, and the extent to which climate change and damages are irreversible.

While scientists have sounded many somber warnings about the longterm peril of unchecked climate change, ${ }^{7}$ the Review attempts to justify strong

${ }^{6}$ This strategy was one of the major conclusions in a review of integrated-assessment models: "Perhaps the most surprising result is the consensus that given calibrated interest rates and low future economic growth, modest controls are generally optimal." David L. Kelly and Charles D. Kolstad, Integrated Assessment Models For Climate Change Control," Henk Folmer and Tom Tietenberg (eds.), International Yearbook of Environmental and Resource Economics 1999/2000: A Survey of Current Issues, Cheltenham, UK, Edward Elgar, 1999.

${ }^{7}$ For a recent warning, see James Hansen, Makiko Sato, Reto Ruedy, Ken Lo, David W. Lea, and Martin Medina-Elizade Global temperature change, Proceedings of the National Academy of Sciences (US), 103, 2006, pp. 14288-14293. 
current action in a cost-benefit economic framework. ${ }^{8}$ Because it has conclusions that are so different from most economic studies, the present note examines the reasons for this major difference. Is this radical revision of global-warming economics warranted?

\section{Overview of the Review}

I will not summarize the basic findings of the Review - a clear summary is found on its website. Instead, I begin with five summary reactions. First, the Review is an impressive document, buttressed by more than a dozen background studies. There is little new science or economics here, but it provides many new syntheses of the extensive and rapidly growing literature. While not as balanced and ponderously reviewed as the reports of the Intergovernmental Panel on Climate Change (IPCC), it is much more current than the latest IPCC report, published in $2001 .{ }^{9}$ For those seriously interested in global warming, it is worth a few days' study.

Second, while I question some of the Review's modeling and economic assumptions, its results are fundamentally correct in sign if not in size. The approach taken in the Review - selecting climate-change policies with an eye to balancing economic needs with environmental dangers - is solidly grounded in mainstream economic analysis. By linking climate-change policies to both economic and environmental objectives, the Review has

\footnotetext{
8 The early precursor of this Review is the study by William R. Cline, The Economics of Global Warming, Washington, Institute for International Economics, 1992.

${ }^{9}$ Contribution of Working Group I to the Third Assessment Report of the Intergovernmental Panel on Climate Change, Climate Change 2001: The Scientific Basis, J. T. Houghton, Y. Ding, D.J. Griggs, M. Noguer, P. J. van der Linden, and D. Xiaosu, eds., Cambridge, Cambridge University Press, 2001.
} 
corrected one of the fundamental flaws of the Kyoto Protocol, which had no such linkage. By contrast, the parallel analysis of the Bush Administration, cited in footnote 2 above, provided no support for the Bush Administration's rejection of binding emissions constraints on GHG emissions.

Third, the Review should be viewed as a political document. Its chief author is Sir Nicholas Stern, who has had a distinguished career in academic and government positions. Until 1993, he was a public-finance economist in British universities specializing in taxation and economic development; today, he is Head of the Government Economics Service and Adviser to the Government. The disciplinary background of a public-finance economist is the leitmotiv running through the chapters. However, it is not an academic study. Like most government reports, the Review was published without an appraisal of methods and assumptions by independent outside experts. But even the analysis of HM Government needs peer review.

The fourth comment concerns the Review's emphasis on the need for increasing the price of carbon emissions. The Review summarizes its discussion here as follows, "Creating a transparent and comparable carbon price signal around the world is an urgent challenge for international collective action." In plain English, the Review argues that it is critical to have a harmonized carbon tax or similar regulatory device both to provide incentives to individual firms and households and to stimulate research and development in low-carbon technologies. Carbon prices must be raised to transmit the social costs of GHG emissions to the everyday decisions of billions of firms and people. This simple yet inconvenient economic insight is virtually absent from most political discussions of climate change policy (including the marathon slide show by Al Gore in An Inconvenient Truth). 
But these points are not the nub of the matter. Rather, and this is the final comment, the Review's radical revision arises because of an extreme assumption about discounting. Discounting is a factor in climate-change policy - indeed in all investment decisions - which involves the relative weight of future and present payoffs. At first blush, this area would appear a technicality that should properly be left to abstruse treatises and graduate courses in economics. Unfortunately, it cannot be buried in a footnote, for discounting is the central to the radical revision. The Review proposes using a social discount rate that is essentially zero. Combined with other assumptions, this magnifies enormously impacts in the distant future and rationalizes deep cuts in emissions, and indeed in all consumption, today. If we were to substitute more conventional discount rates used in other global-warming analyses, by governments, by consumers, or by businesses, the Review's dramatic results would disappear, and we would come back to the climatepolicy ramp described above. The balance of this discussion focuses on this central issue.

\section{The social discount rate: concepts and assumptions}

Discounting involves a concept called the pure rate of social time preference - I will call this "the social discount rate" for short. The social discount rate is a parameter that measures the importance of the welfare of future generations relative to the present. It is calculated in percent per year, like an interest rate, but refers to the discount in future "utility" or welfare, not future goods or dollars. A zero social discount rate means that future generations into the indefinite future are treated equally with present generations; a positive social discount rate means that the welfares of future 
generations are reduced or "discounted" compared to nearer generations. Philosophers and economists have conducted vigorous debates about how to apply social discount rates in areas as diverse as economic growth, climate change, energy policy, nuclear waste, major infrastructure programs such as levees, and reparations for slavery. ${ }^{10}$

Discussions about discount rates need to respect the distinction between the social discount rate and the discount rate on goods. The former refers to the relative weights on different people or generations and is the major source of concern in this note. The latter refers to discounts on bundles of goods and is measured as a "real interest rate." I discuss the connection between these two concepts below.

The sections that follow examine the philosophical arguments about intergenerational equity, how discounting affects the measurement of damages, the role of discounting in economic modeling of climate change, saving behavior, and behavior under uncertainty.

\footnotetext{
${ }^{10}$ Many of the issues involved is discounting, particularly relating to climate change, are discussed in the different studies in Paul Portney and John Weyant, Discounting and Intergenerational Equity, Resources for the Future, Washington, D.C., 1999. Note that the pure rate of social time preference differs from the real interest rate or the discount rate on goods and services, which is in principle observed in the market place. A useful summary is contained in K. J. Arrow, W. Cline, K.G. Maler, M. Munasinghe, R. Squitieri, and J. Stiglitz, "Intertemporal equity, discounting and economic efficiency," in Climate Change 1995 - Economic and Social Dimensions of Climate Change, edited by J. Bruce, H. Lee, and E. Haites, 1996, Cambridge: Cambridge University Press, pp. 125-44.
} 


\section{Philosophical questions about the social discount rate}

At the outset, we should recall the warning that Tjalling Koopmans gave in his pathbreaking analysis of discounting in growth theory. He wrote, "[T] he problem of optimal growth is too complicated, or at least too unfamiliar, for one to feel comfortable in making an entirely a priori choice of [a social discount rate] before one knows the implications of alternative choices."11 This conclusion applies with even greater force in global warming models, which have much greater complexity than the simple, deterministic, stationary, two-input models that Koopmans analyzed.

The Review argues that it is indefensible to make long-term decisions with a positive social discount rate. The conclusion of the approach is the following, "The argument ... and that of many other economists and philosophers who have examined these long-run, ethical issues, is that [a positive social discount rate] is relevant only to account for the exogenous possibility of extinction." (Annex to Chapter 2, p. 52) The argument is that a high social discount rate would lead societies to ignore large costs that occur in the distant future. The actual social discount rate used in the Review is 0.1 percent per year, which is only vaguely justified by extinction estimates; for our purposes, it can be treated as near-zero.

\footnotetext{
${ }^{11}$ Tjalling C. Koopmans, "On the Concept of Optimal Economic Growth," in Pontificiae Academiae Scientiarum Scripta Varia 28, 1, Semaine D'Etude sur Le Role de L'analyse Econometrique dans la Formulation de Plans de Developpement, 1965, pp. 1-75 (available for download at http:// cowles.econ.yale.edu/P/au/p_koopmans.htm.) Zero discounting leads to deep mathematical problems such as non-convergence of the objective function and incompleteness of the functional. For the analytical background, see also Frank Ramsey, "A Mathematical Theory of Saving," Economic Journal, 1928, 38, pp. 543-559; David Cass, "Optimum Growth in an Aggregative Model of Capital Accumulation," Review of Economic Studies, 1965, 32, pp. 233-240.
} 
The logic behind the Review's social welfare function is not as conclusive as it claims. The Review argues that fundamental ethics require intergenerational neutrality using an additive separable logarithmic utility function. Quite another ethical stance would be to hold that each generation should leave at least as much total societal capital (tangible, natural, human, and technological) as it inherited. This would admit a wide array of social discount rates. A third alternative would be a Rawlsian perspective that societies should maximize the economic well-being of the poorest generation. Under this policy, current consumption would increase sharply to reflect likely future improvements in productivity. Yet a fourth perspective would be a precautionary (minimax) principle in which societies maximize the minimum consumption along the riskiest path; this might involve stockpiling vaccines, grain, oil, and water in contemplation of possible plagues and famines. Without choosing among these positions, it should be clear that alternative ethical perspectives are possible. Moreover, as I suggest below, alternative perspectives provide vastly different prescriptions about desirable climatechange policies.

Even if a low social discount is chosen, a second issue arises in the calibration of the social discount rate to actual macroeconomic. Behind the Review's modeling is the assumption that the world economy is in long-run equilibrium of a Ramsey optimal growth model. In a Ramsey equilibrium with stable population, there are two observables - the rate of return on capital and the rate of growth of consumption; and there are two normative parameters - the social discount rate and the curvature of the utility function (more precisely, the elasticity of the marginal utility of consumption). A realistic analysis would also need to account for distortions in the tax system, 
for uncertainties and risk premiums, and for the equity-premium puzzle, but these complications can be ignored in the present context.

The Review assumes a relatively low curvature parameter (the logarithmic utility function) along with the near-zero social discount rate. However, in calibrating a growth model, the social discount rate and the curvature parameter cannot be chosen independently if the model is designed to match observable variables. A low curvature (such as in the logarithmic utility function) implies a relatively high social discount rate. A high curvature (represented by a high degree of risk aversion or a high aversion to intergenerational inequality) implies a low or even negative social discount rate. It turns out that the calibration of the utility function makes an enormous difference to the results in global-warming models, as I show in the modeling section below.

\section{Measuring impacts with near-zero discounting}

With these analytical points behind us, I next discuss the Review's estimates of the aggregate economic impacts. The Review concludes, "Putting these three factors together would probably increase the cost of climate change to the equivalent of a $20 \%$ cut in per-capita consumption, now and forever." This frightening statement suggests that the globe is perilously close to driving off a climatic cliff in the very near future. However, this is an unusual definition of consumption losses, and when the Review says that there are substantial losses "now," this does not mean "today." The measure of consumption used is the "balanced growth equivalents" of consumption. Roughly speaking, with low discounting, this is the certainty equivalent of the average annual consumption loss over the indefinite future. The measure is 
akin to an annuity. In fact, the Review's estimate of the output loss now, as in "today," appears to be zero.

If we look inside the impact boxes, we find some strange things. The damage estimates are much higher than the standard estimates in the impact literature. This probably occurs because of assumptions that tilt up the damage curve: rapid economic growth forever, high economic damage estimates, high climatic impacts of GHG accumulation, catastrophic risks, adverse health impacts, yet higher sensitivity of the climate system, and an adjustment for inequality across countries. Additionally, the Review drew selectively from studies, emphasizing those with high damage estimates, some of which are highly speculative. For example, the Review used estimates from the study of Nordhaus and Boyer (see footnote 12 below) that projected damages way beyond 2100; however, those authors noted that projections beyond 2100 were particularly unreliable.

However, the major point is that these impacts are far into the future, and the calculations depend critically upon the assumption of low discounting. Take as an example the high-climate scenario with catastrophic and non-market impacts. For this case, the mean losses are less than 1 percent of world output in 2050, 2.9 percent in 2100, and 13.8 percent in 2200 (see Figure $6.5 \mathrm{~d})$. Yet this somehow turns into a mean annual impact of 14.4 percent shown in Table 6.1, and after a few other gloomy ingredients are stirred in, it becomes the " $20 \%$ cut in per-capita consumption, now and forever."

How do damages, which average around 5 percent of output over the next two centuries turn into a 14.4 percent reduction in consumption now and 
forever? The answer lies in the way that near-zero discounting magnifies distant impacts. With near-zero discounting, the low damages in the next two centuries get overwhelmed by the long-term average over many centuries. We can illustrate using the Review's model discussed in Box 6.3. Suppose that scientists discover that that a wrinkle in the climatic system will cause damages equal to 0.01 percent of output starting in 2200 and continuing at that rate thereafter.

How large a one-time investment would be justified today to remove the wrinkle starting after two centuries? The answer is that a payment of 15 percent of world consumption today (approximately $\$ 7$ trillion) would pass the Review's cost-benefit test. This seems completely absurd. The bizarre result arises because the value of the future consumption stream is so high with near-zero discounting that we would trade off a large fraction of today's income to increase a far-future income stream by a very tiny fraction. This bizarre implication reminds us of Koopmans's warning quoted above to proceed cautiously to accept theoretical assumptions about discounting before examining their full consequences.

Hence, the damage puzzle is resolved. The large damages from global warming reflect large and speculative damages in the far-distant future; the impacts now, as in today, are small; and, as I will suggest below, the 20 percent cut in consumption from global-warming might be reduced by an order of magnitude if alternative assumptions about discounting are used. 


\section{Economic modeling with low discount rates}

I next apply these points in an empirical model of the economics of global warming. To foreshadow the result, these calculations show that the assumption of a near-zero social discount rate drives most of the economic results in the Review.

It is virtually impossible for mortals outside the group that did the modeling to understand the detailed results of the Review. It would involve studying the economics and geophysics in several chapters, taking apart a complex analysis (the PAGE model), and examining the derivation and implications of each of the economic and scientific judgments.

The alternative approach followed here is to use a small and welldocumented model of the economics of climate change to estimate the optimal policy, and then to make parameter adjustments to parallel assumptions made in the Review. For this purpose, I use the "DICE model," which is an acronym for a Dynamic Integrated model of Climate and the Economy. This model, developed in the early 1990s, uses a simple dynamic representation of the scientific and economic links among population, technological change, GHG emissions, concentrations, climate change, and damages. The analytical structure of the DICE model is identical to that in the Review. DICE calculates the paths of capital investment and GHG reductions that maximize a social welfare function, where the social welfare function is the discounted sum of population-weighted utilities of per capita consumption. The DICE model assumes a pure rate of social time preference starting at 3 percent per year and declining slowly to about 1 percent per year in 300 years. The social discount 
rate was chosen to be consistent with a logarithmic utility function, market interest rates, and rates of private and public saving and investment. ${ }^{12}$

For this analysis, I have updated the DICE model to 2005 data, economics, science, and 2006 prices. ${ }^{13}$ I then make three runs, which are explained as we proceed:

Run 1. Optimal climate change policy in the DICE-2006 model

Run 2. Optimal climate change using the Stern Review zero discount rate

Run 3. Optimal climate change using a recalibrated zero discount rate

Run 1. Run 1 is the Optimal climate change policy in DICE-2006. This run takes the DICE-2006 model and calculates the optimal trajectory of climate change policies as described above. This calculation leads to an optimal carbon price in 2005 of $\$ 17.12$ per ton $C$, rising over time to $\$ 84$ in 2050 and $\$ 270$ in 2100. (The "optimal carbon price," or carbon tax, sometimes called the "social cost of carbon," is the calculated price of carbon emissions that will balance the incremental costs of reducing carbon emissions with the

${ }^{12}$ Results and documentation of the DICE model are provided in William Nordhaus, "An Optimal Transition Path for Controlling Greenhouse Gases," Science, vol. 258, November 20,1992, pp. 1315-1319; William Nordhaus, Managing the Global Commons: The Economics of Climate Change, MIT Press, Cambridge, Mass., 1994; William Nordhaus and Zili Yang "A Regional Dynamic General-Equilibrium Model of Alternative Climate-Change Strategies," , American Economic Review, vol. 86, No. 4, September 1996, pp. 741-765; William Nordhaus and Joseph Boyer, Warming the World: Economic Modeling of Global Warming, MIT Press, Cambridge, Mass, 2000; William Nordhaus, "Global Warming Economics," Science, November 9, 2001, vol. 294, no. 5545, pp. 1283-1284.

${ }^{13}$ Documentation of the changes in the DICE-2006 model and the GAMS computer program for the DICE-2006 model are provided in William D. Nordhaus, "Documentation for DICE-2006, November 2006 round," November 17, 2006, available at www.nordhaus.econ.yale.edu , under "Recent Stuff." 
incremental benefits of reducing climate damages.) The optimal rate of emissions reduction is 6 percent in 2005, 14 percent in 2050, and 25 percent in $2100 .{ }^{14}$ This optimized path leads to a projected global temperature increase from 2000 to 2100 of around 1.8 degrees C. While the findings of such mainstream economic assessments may not satisfy the most ardent environmentalists, if followed they would go far beyond current global emissions reductions and would be a good first step on a journey of many miles.

Run 2. The results of the standard DICE model just discussed are completely different from those in the Review. The Review recommends a social cost of carbon of $\$ 311$ per ton $\mathrm{C}$. This number is almost 20 times the DICE model result. Based on calculations made in earlier publications (see footnote 12), it seems likely that the major reason for the Review's sharp emissions reductions and high carbon price is the low social discount rate. I therefore calculated run 2, Optimal climate change using the Stern Review zero discount rate. The assumptions are the same as Run 1 except that the social discount rate is changed to 0.1 percent per year. This dramatically changes the trajectory of climate-change policy. The 2005 optimal carbon price in the DICE model rises from $\$ 17.12$ in Run 1 to $\$ 159$ per ton C in Run 2.15 Efficient emissions reductions in Run 2 are much larger - with emissions reductions of

14 The future numbers are the solutions to the model based on current information and provide estimates of optimal future policies under current estimates of parameters. They are not decisions that are taken today. They should be revised over time as new scientific and economic information becomes available.

15 The social cost of carbon estimated in the Review is approximately two times higher than the number calculated in Run 2. Because different models are used, it is not possible to identify reasons for the discrepancy. Modeling results are extremely sensitive to parameter changes when the discount rate is near-zero. 
50 percent in 2015 - because future damages are in effect treated as occurring today. The climate-policy ramp flattens out.

Run 3.An earlier section noted that alternative calibrations of the social welfare function are consistent with observable variables. So the final run is one in which assumes a low social discount rate but where the curvature parameter is calibrated so that the economic growth path conforms to observable variables. Some history might be helpful here. When the DICE model was constructed fifteen years ago, I assumed logarithmic utility for computational reasons - alternative utility functions would not converge numerically. This calibration led to a social discount rate of 3 percent per year, which was calibrated to match the growth of consumption, savings rates, and market rates of return on capital. Because of improvements in computers and software, we can now easily calibrate alterative utility functions. Experiments with the DICE-2006 model indicate that a social discount rate of 0.1 percent per year is consistent with a utility curvature parameter of 2.25. However, the Review's social discount rate of 0.1 percent per year is inconsistent with its utility curvature assumption of $1 .^{16}$ The Review's calibration gives too low a rate of return and too high a savings rate compared to macroeconomic data,

16 The discussion in the text assumes zero population growth. More generally, the Ramsey-Cass-Koopmans steady-state optimal growth equilibrium equation is $r=\rho+a g+n$, where $r=$ the marginal product of capital, $\rho=$ social discount rate, $\alpha=$ elasticity of the marginal utility of consumption, $g=$ growth of per capita consumption, and $\mathrm{n}=$ rate of growth of population. Conceptually, the marginal product of capital has the same units as the real interest rate, but entirely different units from the social discount rate. To apply this equilibrium condition, assume that the observable variables (in rates per year) are $r=0.05, n=0.00$, and $g=0.02$. For this simplest equation, if we assume that the social discount rate is $\rho=0$ per year, then $a$ $=2.5$. If we take the log-linear utility function of the Review together with the observable variables in this footnote, then this implies that $\rho=0.03$ per year. The calibrations in DICE-2006 are slightly different from these equilibrium calculations because of positive population growth and non-constant consumption growth, but these equilibrium calculations given the flavor of the results. 
but the alternative calibration proposed here fits the macroeconomic data underlying the DICE model.

We can now rerun the DICE-2006 model with the near-zero social discount rate and the associated calibrated curvature parameter derived in the last paragraph. This is Run 3, Optimal climate change with recalibrated zero discount rate. Run 3 looks very similar to Run 1, the standard DICE-2006 model optimal policy. The first-period social cost of carbon in Run 3 is $\$ 19.55$ per ton C, slightly above Run 1 . The recalibrated run looks nothing like Run 2, which is the run that reflects the Review's assumption. How can it be that Run 3, with a near-zero social discount rate, looks so much like Run 1 ? The reason is that the recalibrated social discount rate in Run 3 maintains the assumption of productive capital, with a relatively high real interest rate in the near term. This high return means that the logic of the climate-policy ramp continues to hold even though the social choice function has been recalibrated to a zero social discount rate. This calibration removes the cost-benefit dilemmas just discussed as well as the savings and uncertainty problems discussed in the next two sections.

\section{Implications for saving and investment}

I return for the balance of this note to the Review's assumptions on both social discount rate and utility curvature (the assumptions that underlie Run 2). One surprising implication of the Review's social discount rate is the effect on consumption and saving. If the Review's philosophy were adopted as a general policy, it would produce much higher overall saving as compared with today. In Run 2 (Optimization with Stern discount parameter), the global net savings rate almost doubles compared to the historical numbers or Run 1 . This 
implies that global consumption would be reduced by about 14 percent, requiring a reduction of $\$ 6$ trillion per year in current consumption.

Where would the consumption cuts come from? From India and Africa? That hardly seems equitable. The higher investment would be more than five times total overseas development aid of all countries today. Perhaps the consumption should come from the wasteful Americans? This would be fourfifths of current levels of consumption and many times the decline in the Great Depression.

Aside from the question of who pays, we might wonder whether such a large decline in current consumption today is desirable in a world where average consumption is growing rapidly. The Review projects that per capita consumption will grow at 1.3 percent per year over the next two centuries ( $p$. 162). In 2006 dollars, this means that today's per capita consumption of $\$ 7,600$ would grow to $\$ 94,000$ in 2200 . Here perhaps is a shard of hope for the globe.

However, this growth also means that future climatic damages will come out of a much higher level of income. For example, the high-damage case is associated with a 13.8 percent decline in consumption in 2200 as discussed above. This means that per capita consumption would grow from $\$ 7,800$ today to only $\$ 81,000$ in 2200 . Hence, the Review advocates reducing current consumption to prevent the decline in consumption of future generations that it projects to be much richer than today. While this might be worth contemplating, it hardly seems ethically compelling.

Faced with these implications of the discounting assumption, advocates of the Review policy might propose a "dual-discounting" approach - limiting 
the scope of the low social discount rate to climate policy. In other words, perhaps countries should choose global-warming policies assuming the nearzero social discount rate, but leave the rest of the economy to operate with the present high social discount rate. While this seems an attractive possibility, it is in fact a roundabout way to slow climate change sharply. In effect, we are using a low social discount rate to "prevent dangerous interference with the climate system" (in the language of the Framework Convention on Climate Change). If that is the reason, why not impose the limit directly? Instead of using the near-zero social discount rate as an analytic subterfuge to slow climate change, why not simply adopt policies that will directly keep climate change below the dangerous threshold? Limiting climate change directly is more efficient as well as more transparent.

\section{Hair triggers and uncertainty}

A further unattractive feature of the Review's near-zero social discount rate is that it puts present decisions on a hair-trigger in response to far-future contingencies. Under conventional discounting, contingencies many centuries ahead have a tiny weight in today's decisions. Decisions focus on the near future. With the Review's discounting procedure, by contrast, present decisions become extremely sensitive to uncertain events in the distant future.

We saw above how an infinitesimal impact on the post-2200 income stream could justify a large consumption sacrifice today. We can use the same example to illustrate how far-future uncertainties are magnified by low discount rates. Suppose that we suddenly learn that there is a 10 percent probability of the wrinkle in the climatic system that reduces the post-2200 income stream by 0.01 percent. What insurance premium would be justified 
today to reduce that probability to zero? With conventional discount rates, we would probably ignore any tiny wrinkle two or three centuries ahead. If we did a careful calculation using conventional discount rates, we would calculate a breakeven 0.0002 percent insurance premium to remove the year2200 contingency, and a 0.0000003 percent premium for the year- 2400 contingency. Moreover, these dollar premiums are small whether the probability is large or small.

With the Review's near-zero discount rate, offsetting the low-probability wrinkle would be worth an insurance premium today of almost 2 percent of current income, or $\$ 1$ trillion. We would pay almost the same amount if that threshold were to be crossed in 2400 rather than in 2200. Because the future is so greatly magnified by a near-zero social discount rate, policies would be virtually identical for different threshold dates. Moreover, a small refinement in the probability estimate would trigger a large change in the dollar premium we would pay. We are in effect forced to make current decisions about highly uncertain events in the distant future even though these estimates are highly speculative and are almost sure to be refined over the coming decades.

While this feature of low discounting might appear benign in climatechange policy, we could imagine other areas where the implications could themselves be dangerous. Imagine the preventive war strategies that might be devised with low social discount rates. Countries might start wars today because of the possibility of nuclear proliferation a century ahead; or because of a potential adverse shift in the balance of power two centuries ahead; or because of speculative futuristic technologies three centuries ahead. It is not clear how long the globe could long survive the calculations and machinations 
of zero-discount-rate military powers. This is yet a final example of a surprising implication of a low discount rate.

\section{Summary verdict}

How much and how fast should the globe reduce greenhouse-gas emissions? How should nations balance the costs of the reductions against the damages and dangers of climate change? The Stern Review answers these questions clearly and unambiguously: we need urgent, sharp, and immediate reductions in greenhouse-gas emissions.

I am reminded here of President Harry Truman's complaint that his economists would always say, on the one hand this and on the other hand that. He wanted a one-handed economist. The Stern Review is a Prime Minister's dream come true. It provides decisive and compelling answers instead of the dreaded conjectures, contingencies, and qualifications.

However, a closer look reveals that there is indeed another hand to these answers. The radical revision of the economics of climate change proposed by the Review does not arise from any new economics, science, or modeling. Rather, it depends decisively on the assumption of a near-zero social discount rate. The Review's unambiguous conclusions about the need for extreme immediate action will not survive the substitution of discounting assumptions that are consistent with today's market place. So the central questions about global-warming policy - how much, how fast, and how costly - remain open. The Review informs but does not answer these fundamental questions. 